\title{
Is qualitative research under-represented in ophthalmology journals?
}

Eye (2017) 31, 1117-1119; doi:10.1038/eye.2017.49; published online 7 April 2017

There has been a recent recognition that qualitative research methods have an important place in health research. ${ }^{1}$ Qualitative research encompasses a wide range of different research methodologies and types of data in order to answer questions about 'why?' or 'how?' as opposed to quantitative research that typically seeks to ask questions of 'how many?' or 'how much?' Qualitative and quantitative research methods are traditionally based on different views of knowledge (epistemological views) for example, a quantitative researcher might have a positivist view (there is absolute truth that is objective and neutral) and a qualitative researcher a constructivist view (the reality we perceive is constructed by our social, historical, political, and individual contexts; there are no stable pre-existing phenomena). ${ }^{2,3}$ However, for many of us who work in healthcare, our view may lie somewhere in the middle; we are 'realists' or 'post-positivists' (there is a truth or reality that can be discovered but all observation is fallible and researchers cannot be truly neutral, social context is important). For those of us who do not hold a strict positivist view, then we are likely to find value in qualitative research outcomes. However, qualitative research methods may seem quite alien to those of us with a traditional health research background, particularly in ophthalmological or vision sciences. Eye seeks to 'support medical professionals in the delivery of excellent ophthalmic services and healthcare.' In some cases, this may warrant the publication of highquality studies using qualitative methodologies. If this is the case, as a readership we need to better understand how to critically appraise and peer review such articles in order to aid their publication.
We wanted to determine whether there was a discrepancy between the number of highquality, funded qualitative research studies being conducted in the United Kingdom and those being published in journals such as Eye during recent years. We identified funded research within ophthalmology or vision sciences using the UK Clinical Research Network (UKCRN) portfolio database, which consists of high-quality, fully funded clinical research studies in the United Kingdom. Studies closed to recruitment between January 2010 and December 2015 were reviewed and classified as using qualitative, quantitative, mixed, or other methods by two independent assessors. If there was uncertainty in relation to the research method used the principal investigator was contacted. We then went through all the issues of Eye for the years 2014-2016 inclusive and again assessed how many articles used qualitative research methods. We did the same for two other ophthalmic journals: another UK-based journal, The British Journal of Ophthalmology, and Ophthalmology, which is the journal of the American Academy of Ophthalmology. We included articles under the titles of 'clinical studies', 'clinical science' or 'global perspectives', and 'original articles' for Eye, the BJO, and Ophthalmology, respectively.

We found that $16 / 150(11 \%)$ of identified studies on the UKCRN portfolio used qualitative research methods (9 pure qualitative studies and 7 mixed methods). Of the studies published in Eye, 4/442 (0.9\%) used qualitative methods; in the $B J O, 0 / 750(0 \%)$ used qualitative methods; and in Ophthalmology, 2/773 (0.3\%) used qualitative methods. Overall, across the three journals, 6/1965 (0.3\%) published research studies during the time period screened included qualitative methods.

The data suggest that high-quality qualitative research is being funded and conducted in ophthalmology and vision sciences. These studies or similar are rarely published in 
Table 1 Examples of qualitative research studies in ophthalmology and what they have added to our knowledge

\begin{tabular}{|c|c|}
\hline Lacey et $a l^{4}$ & $\begin{array}{l}\text { Identify important barriers to compliance with glaucoma medication. This enables generation of theories of } \\
\text { how to improve drop compliance. }\end{array}$ \\
\hline Saedon $^{5}$ & $\begin{array}{l}\text { Identify deficiencies and positives in feedback from trainers to trainees whilst learning cataract surgery, again } \\
\text { enabling generation of theories to improve training. }\end{array}$ \\
\hline Jefferis et $a l^{6}$ & $\begin{array}{l}\text { Exploration of anaesthetic practices for cataract surgeons operating on people with dementia. The qualitative } \\
\text { methods allow presentation of different views without erasing differing perspectives as well as the unpicking } \\
\text { of a complex, multidimensional topic. }\end{array}$ \\
\hline Vin et $a l^{7}$ & $\begin{array}{l}\text { Use qualitative methods to create comprehensive individual profiles so that care can be tailored to individuals } \\
\text { to improve compliance with anti-glaucoma medication. The qualitative methods enable individualised care at } \\
\text { the highest level. }\end{array}$ \\
\hline Glen and $\mathrm{Crabb}^{8}$ & $\begin{array}{l}\text { Investigated coping strategies used by glaucoma patients with visual loss, enabled in depth look at a complex } \\
\text { and multidimensional issue for individuals. }\end{array}$ \\
\hline Kotecha et $a l^{9}$ & $\begin{array}{l}\text { Explored patient perceptions of glaucoma virtual clinics compared to the standard face-to-face consultant led } \\
\text { clinics. Recognising that patient perceptions and not just visual outcomes are an important aspect of providing } \\
\text { best care. }\end{array}$ \\
\hline McCloud and Lake ${ }^{10}$ & $\begin{array}{l}\text { Studied patient experiences of treatment for wet macular degeneration, and the burdens and anxieties } \\
\text { associated with this treatment. This enables clinicians to be mindful of these when counselling patients about } \\
\text { intensive treatment regimes for wet macular degeneration. }\end{array}$ \\
\hline Steeples et al ${ }^{11}$ & $\begin{array}{l}\text { Used thematic analysis of data from wrong IOL patient safety incident reports to explore some of the reasons } \\
\text { that these errors were made. This analysis method allowed the investigators to identify important patterns and } \\
\text { recurring themes which may contribute wrong IOL events. }\end{array}$ \\
\hline Castañeda et $a l^{12}$ & $\begin{array}{l}\text { Explored the concerns of children with cataracts and their parents. Enabled them to identify the impact of } \\
\text { cataract on physical, social, and emotional functioning. This information can be used to develop measures of } \\
\text { quality of life and visual functioning for children with cataract. }\end{array}$ \\
\hline
\end{tabular}

Box 1 CASP guidance on how to critically appraise a qualitative paper: 10 questions to help you make sense of qualitative research (www.CASP-uk.net)

1. Was there a clear statement of the aims of the research?

2. Is the qualitative methodology appropriate?

3. Was the research design appropriate to address the aims of the research?

4. Was the recruitment strategy appropriate to the aims of the research?

5. Was the data collected in a way that addressed the research issue?

6. Has the relationship between researcher and participants been adequately considered?

7. Have ethical issues been taken into consideration?

8. Was the data analysis sufficiently rigorous?

9. Is there a clear statement of findings?

10. How valuable is the research?

ophthalmology journals, although Eye did publish more than either the BJO or Ophthalmology. Published qualitative studies in ophthalmology and vision sciences whilst reasonably scarce have contributed knowledge and understanding in the past which would be impossible to glean from quantitative studies alone (see some examples in Table 1). It is important that we do not miss out on important information because of our lack of understanding of the research methods used. In the same way that we are trained and practiced at critically appraising quantitative research methods, we need to be able to critically appraise qualitative work. The Critical Appraisals Skill Programme (www.CASP-uk.net) has published guidelines on how to do this (summarised in Box 1). Although qualitative research has its clear limitations, we believe that it has a place in ophthalmology and vision science research, and think that we should expect to see a few $(<10 \%)$ wellconducted, well-written qualitative research studies published in ophthalmic journals.

\section{Conflict of interest}

The authors declare no conflict of interest.

\section{References}

1 Green J, Thorogood N. Qualitative Methods for Health Research. 2nd edn. Sage: London, 2009.

2 Kuper A, Reeves S, Levinson W. An introduction to reading and appraising qualitative research. BMJ 2008; 337: a288.

3 Crotty M. The Foundations of Social Research. Sage: London, 1998.

4 Lacey J, Cate H, Broadway DC. Barriers to adherence with glaucoma medications: a qualitative research study. Eye 2009; 23(4): 924-932.

5 Saedon H. An analysis of ophthalmology trainees' perceptions of feedback for cataract surgery training. Clin Ophthalmol 2014; 8: 43-47.

6 Jefferis JM, Clarke MP, Taylor JP, Brittain KR. Challenges for the cataract surgeon treating people with dementia: a 
qualitative study exploring anesthetic choices. Clin Ophthalmol 2014; 8: 1993-1999.

7 Vin A, Schneider S, Muir KW, Rosdahl JA. Health coaching for glaucoma care: a pilot study using mixed methods. Clin Ophthalmol 2015; 9: 1931-1943.

8 Glen FC, Crabb DP. Living with glaucoma: a qualitative study of functional implications and patients' coping behaviours. BMC Ophthalmol 2015; 15: 128.

9 Kotecha A, Bonstein K, Cable R, Cammack J, Clipston J, Foster P. Qualitative investigation of patients' experience of a glaucoma virtual clinic in a specialist ophthalmic hospital in London, UK. BMJ Open 2015; 5(12): e009463.

10 McCloud C, Lake S. Understanding the patient's lived experience of neovascular age-related macular degeneration: a qualitative study. Eye 2015; 29(12): 1561-1569.

11 Steeples LR, Hingorani M, Flanagan D, Kelly SP. Wrong intraocular lens events-what lessons have we learned? A review of incidents reported to the National Reporting and
Learning System: 2010-2014 versus 2003-2010. Eye 2016; 30(8): 1049-1055.

12 Castañeda YS, Cheng-Patel CS, Leske DA, Wernimont SM, Hatt SR, Liebermann L et al. Quality of life and functional vision concerns of children with cataracts and their parents. Eye 2016; 30(9): 1251-1259.

RK Jones and JM Jefferis

Department of Ophthalmology, Royal Hallamshire Hospital, Sheffiled, UK

Correspondence: RK Jones, Department of Ophthalmology, Royal Hallamshire Hospital, Glossop Road, Sheffiled S10 2JF, UK

Tel: +44 (0)114 271 2036; Fax: +44 (0)114 2713682 . E-mail: ruth.jones@doctors.org.uk 